\title{
Takotsubo syndrome caused by subconjunctival injection of a mydricaine analogue
}

Sulakshan Rasiah BMBS, ${ }^{1}$ Robert P Finger MD PhD, ${ }^{1,2}$ Andrew I Macl saac FRACP ${ }^{3}$ and Lyndell LP Lim DMedSci FRANZCO ${ }^{1,2}$

${ }^{1}$ Royal Victorian Eye and Ear Hospital, Melbourne, VIC, Australia

${ }^{2}$ Centre for Eye Research Australia, University of Melbourne, VIC, Australia

${ }^{3}$ St. Vincent's Hospital, Melbourne, VIC, Australia

Correspondence: Dr Sulakshan Rasiah, 231 Brandon Park Drive, Wheelers Hill, VIC 3150 Australia

E-mail: sulakshan.rasiah@gmail.com

Received 16 December 2015; accepted 6 February 2016

Financial Support: None

Conflict of Interest: None



This is the author manuscript accepted for publication and has undergone full peer review but has not been through the copyediting, typesetting, pagination and proofreading process, which may lead to differences between this version and the Version of Record. Please cite this article as doi: 10.1111/ceo.12729

This article is protected by copyright. All rights reserved. 
A 45 year old female with recurrent HLA-B27 anterior uveitis presented with imminent seclusio pupillae from extensive posterior synechiae in her right eye. She had a history of ankylosing spondylitis, treated with 10mg of Methotrexate weekly. She had no previous cardiac history or cardiovascular risk factors.

After intensive topical mydriatics failed to break down the synechiae ( 2 drops Tropicamide $0.5 \%$ followed by 3 drops Phenylephrine $10 \%$ ), a hospital formulation of mydricaine was injected subconjunctivally ( $2 \mathrm{mg}$ atropine sulphate in $0.2 \mathrm{~mL}$, $200 \mathrm{mcg}$ adrenaline in $0.2 \mathrm{~mL}$ and $12 \mathrm{mg}$ lignocaine in $0.6 \mathrm{~mL}$; administration of $1 \mathrm{~mL}$ in four $0.25 \mathrm{~mL}$ blebs). This non-standard formulation of mydricaine has historically been used at this hospital to prevent seclusio pupillae, and occasionally for vitreoretinal surgery, for many years. The rationale for the use of this specific formulation, which contains far more atropine and adrenaline when compared to the more commonly used Moorfields Mydricaine No 2 (1mg atropine, 120mcg adrenaline, $6 \mathrm{mg}$ procaine), remains undetermined.

I mmediately following the injection, the patient felt faint and drowsy. She became hypertensive and tachycardic. Fifteen minutes later she developed chest tightness. An ECG showed ST depression in leads II and V4-6 and subsequent serum Troponin levels peaked at 530. She was urgently transferred to the nearest tertiary hospital, where she was admitted under the Cardiology unit with suspicion of an acute inferior myocardial infarct.

An angiogram was performed the following day, which found normal coronary arteries and severe hypokinesis of the mid-to-anterior left ventricle in the distribution of multiple coronary arteries. This finding is consistent with Takotsubo or Stress cardiomyopathy. The patient was discharged home with medical management (beta-blocker, statin and ACE inhibitor), to continue for three months. On discharge, the patient's symptoms had resolved and the ECG had normalised.

We present the first documented case of Takotsubo cardiomyopathy induced by subconjunctival injection of mydricaine. 
Takotsubo cardiomyopathy is a coronary dysfunction first described in 1990 and typified by hypokinetic regions of the left ventricle which is often transient. ${ }^{1,2}$ It presents with a similar clinical picture to an acute coronary syndrome - with patients having chest pain, ECG changes and elevated serum troponin levels - but lacks acute obstructive disease of the coronary arteries. ${ }^{1,2}$ It is a relatively rare condition, mostly affecting women ( $>89 \%$ of cases) and not linked to any past medical history, often occurring in patients who are otherwise fit and well. ${ }^{1,2}$ Takotsubo cardiomyopathy, otherwise known as "broken-heart syndrome", has traditionally been associated with emotional stress. However, it has been shown recently that a physical trigger or a combination of physical and emotional triggers are more likely to cause the event, although the specific pathophysiology of this syndrome is not well understood. ${ }^{1}$

Mydricaine is a mydriatic medication first formulated in Moorfields Eye Hospital, and is most frequently used to cause mydriasis following vitreoretinal surgery or to dislodge posterior synechiae in uveitis. Cardiac side-effects are a well-documented risk of its administration, with coronary events, arrhythmias and hypertension most commonly described. ${ }^{2,3,4}$ In this case, it is unclear whether the cardiomyopathy was caused by emotional stress, the injected medications, or a combination of both. Two case series have been published in recent years examining the cardiac side effects of subconjunctival mydricaine. The first, published by Jayamanne and colleagues found a significant change in heart rate between the study group and control group ${ }^{3}$ following subconjunctival mydricaine. However, all documented side effects were self-limiting and required no further treatment. Six patients in the study group (20\%) also developed self-limiting cardiac arrhythmias as a direct result of mydricaine injection. The second case series was published by Steel and colleagues with similar results. ${ }^{4}$ Like the prior study, a significant proportion (20\%) of their study group developed self-limiting cardiac arrhythmias (20\%) after subconjunctival mydricaine. Once again, no long term effects were described. 
A single case report in 2005 described acute myocardial ischaemia following subconjunctival injection of mydricaine, on a background of no previous cardiac illness. ${ }^{5}$ The effect was a transient tachycardia, chest pain and ST elevation on ECG, which resolved after 10 minutes. This is the only published case of cardiac injury following subconjunctival mydricaine. All of these cases used a mydricaine formulation standardised by Moorfields Eye Hospital, which has lower doses of adrenaline and atropine than used in this case (see above).

We believe the high dose of adrenaline used, combined with the stress and discomfort of subconjunctival injection, is the most likely cause of Takotsubo cardiomyopathy in this case. There are currently multiple hypotheses attempting to describe the pathophysiology of Takotsubo cardiomyopathy, including theories that it is a protective adaptation to cardiac overstimulation, with experiments in rat models showing that elevated levels of serum adrenaline can induce the effect. ${ }^{2}$ The high concentration of vasculature in the conjunctiva also further increases the risk of subconjunctival mydricaine injections resulting in systemic effects. A subconjunctival injection of $1.0 \mathrm{~mL}$ is extremely uncomfortable, despite topical and local anaesthetic, and is sufficient to cause significant physical and emotional stress.

As a result of this case, the use of subconjunctival mydricaine has been ceased in this hospital's emergency department, and limited elsewhere within the hospital. An alternative form of controlled topical adrenaline has been proposed. We would recommend that further use of subconjunctival mydricaine should not only be judicious, but only performed in a setting where tertiary medical services can be easily accessed. 


\section{REFERENCES}

1. Templin C, Ghadri J R, Diekmann J, et al. Clinical Features and Outcomes of Takotsubo (Stress) Cardiomyopathy. New England Journal of Medicine. 2015;373(10):929-938. doi:10.1056/NEJ Moa1406761.

2. Redfors B, Shao Y, Ali A, Omerovic E. Current hypotheses regarding the pathophysiology behind the takotsubo syndrome. International Journal of

= Cardiology. 2014;177(3):771-779. doi:10.1016/j.ijcard.2014.10.156.

3. Jayamanne DG, Ray-Chaudhuri N, Wariyar R, Cottrell DG. Haemodynamic responses to subconjunctival mydriatic agents (Mydricaine) used for maintenance of perioperative mydriasis in patients undergoing vitreoretinal surgery. Eye. 1998; 12 ( Pt 5):792-794. doi:10.1038/eye.1998.205.

4. Steel DH, Thorn J. The incidence of systemic side-effects following subconjunctival Mydricaine no. 1 injection. Eye (London, England). 1999;13 ( Pt 6):720-722. doi:10.1038/eye.1999.214.

5. Keembiyage RD, Newland HS, Lai C. Tachycardia and myocardial ischaemia following subconjunctival injection of mydricaine (number 02) for vitrectomy procedure [5]. Clinical and Experimental Ophthalmology. 2005;33(1):105-106. doi:10.1111/j.1442-9071.2005.00960.x.

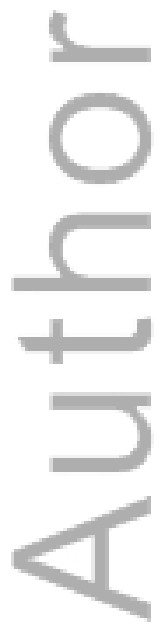




\section{University Library}

\section{- M M N E R VA A gateway to Melbourne's research publications}

Minerva Access is the Institutional Repository of The University of Melbourne

Author/s:

Rasiah, S;Finger, RP;Maclsaac, Al;Lim, LLP

Title:

Takotsubo syndrome caused by subconjunctival injection of a mydricaine analogue

Date:

2016-09-01

Citation:

Rasiah, S., Finger, R. P., Maclsaac, A. I. \& Lim, L. L. P. (2016). Takotsubo syndrome caused by subconjunctival injection of a mydricaine analogue. CLINICAL AND EXPERIMENTAL OPHTHALMOLOGY, 44 (7), pp.624-625. https://doi.org/10.1111/ceo.12729.

Persistent Link:

http://hdl.handle.net/11343/291153 